OPEN ACCESS

Edited by: Aldo Venuti,

Regina Elena National Cancer Institute, Hospital Physiotherapy Institutes (IRCCS), Italy

Reviewed by:

Santo Landolfo,

University of Turin, Italy

David H. McDermott,

National Institutes of Health $(\mathrm{NIH})$,

United States

*Correspondence: Margherita Doria

doria@uniroma2.it

${ }^{\text {t}}$ These authors have contributed equally to this work and share first authorship

FThese authors have contributed equally to this work and share

senior authorship

Specialty section: This article was submitted to Primary Immunodeficiencies,

a section of the journal

Frontiers in Immunology

Received: 21 October 2021 Accepted: 10 January 2022 Published: 26 January 2022

Citation:

Doria M, Moscato GMF, Di Cesare S, Di Matteo G, Sgrulletti M, Bachelerie F,

Marin-Esteban $V$ and Moschese $V$ (2022) Case Report: Altered NK Cell Compartment and Reduced CXCR4

Chemotactic Response of $B$

Lymphocytes in an Immunodeficient Patient With HPV-Related Disease.

Front. Immunol. 13:799564. doi: 10.3389/fimmu.2022.799564

\section{Case Report: Altered NK Cell Compartment and Reduced CXCR4 Chemotactic Response of B Lymphocytes in an Immunodeficient
Patient With HPV-Related Disease}

\author{
Margherita Doria $^{1 \star t}$, Giusella M. F. Moscato ${ }^{2 \dagger}$, Silvia Di Cesare ${ }^{1}$, Gigliola Di Matteo ${ }^{3}$, \\ Mayla Sgrulletti ${ }^{4,5}$, Françoise Bachelerie ${ }^{6}$, Viviana Marin-Esteban ${ }^{6 \neq}$ and Viviana Moschese ${ }^{4 \neq}$ \\ ${ }^{1}$ Research Unit of Primary Immunodeficiency, Bambino Gesù Children's Hospital, Istituto di Ricerca e Cura a Carattere \\ Scientifico (IRCCS), Rome, Italy, ${ }^{2}$ Infectious Diseases Unit, Policlinico Tor Vergata, University of Tor Vergata, Rome, Italy, \\ ${ }^{3}$ Department of Medicine of Systems, University of Tor Vergata, Rome, Italy, ${ }^{4}$ Pediatric Immunopathology and Allergology \\ Unit, Policlinico Tor Vergata, University of Tor Vergata, Rome, Italy, ${ }^{5}$ PhD Program in Immunology, Molecular Medicine and \\ Applied Biotechnology, University of Rome Tor Vergata, Rome, Italy, ${ }^{6}$ Université Paris-Saclay, Inserm, Inflammation, \\ Microbiome and Immunosurveillance, Clamart, France
}

The study of inborn errors of immunity (IEI) provides unique opportunities to elucidate the microbiome and pathogenic mechanisms related to severe viral infection. Several immunological and genetic anomalies may contribute to the susceptibility to develop Human Papillomavirus (HPV) pathogenesis. They include different acquired immunodeficiencies, EVER1-2 or CIB1 mutations underlying epidermodysplasia verruciformis (EV) syndrome and multiple IEl. Whereas EV syndrome patients are specifically unable to control infections with beta HPV, individuals with IEI show broader infectious and immune phenotypes. The WHIM (warts, hypogammaglobulinemia, infection, and myelokathexis) syndrome caused by gain-of-CXCR4-function mutation manifests by HPV-induced extensive cutaneous warts but also anogenital lesions that eventually progress to dysplasia. Here we report alterations of B and NK cells in a female patient suffering from cutaneous and mucosal HPV-induced lesions due to an as-yet unidentified genetic defect. Despite no detected mutations in CXCR4, B but not NK cells displayed a defective CXCR4-dependent chemotactic response toward CXCL12. In addition, NK cells showed an abnormal distribution with an expanded CD56 $6^{\text {bright }}$ cell subset and defective cytotoxicity of CD56 ${ }^{\text {dim }}$ cells. Our observations extend the clinical and immunological spectrum of IEI associated with selective susceptibility toward HPV pathogenesis, thus providing new insight on the immune control of HPV infection and potential host susceptibility factors.

Keywords: WHIM, CXCR4/CXCL12 axis, B lymphocytes, NK cells, HPV 


\section{INTRODUCTION}

More than 200 types of human papilloma virus (HPV) ordered into 5 genera have been recognized and classified as cutaneous or mucosal according to their tropism (1). The alpha genus comprises HPV types mostly associated with the development of anogenital and oropharyngeal carcinomas whereas the beta genus can be associated with cutaneous squamous cell carcinoma. Patients with EV, a rare genodermatosis due to mutations of the EVER1/EVER2/CIB1 trans-membrane channel proteins, develop persistent disseminated beta HPV-derived verrucous cutaneous lesions in sun-exposed areas that might become malignant later in life (2). These patients show normal adaptive immunity while their exclusive susceptibility to develop HPV-related disease might be linked to epithelial homeostasis (2). Recent years have seen growing evidence of recurrent and severe non-beta genus restricted HPV infections among immunosuppressed individuals with $\mathrm{T}$ cell primary immunodeficiency (3). Several germline mutations causing IEI, such as those affecting CXCR4, GATA2, SASH3 and WAS, have been associated with disseminated cutaneous and anogenital HPV-induced pathology $(3,4)$.

The identification of CXCR4 gain of function mutations in the etiology of the WHIM syndrome has expanded our knowledge of the physiopathology of this receptor and its CXCL12 chemokine ligand. In WHIM, premature termination or frameshift mutations in the cytoplasmic tail of CXCR4 prevent receptor internalization/ desensitization in response to CXCL12 binding, which accounts for enhancement of CXCR4 expression and chemotactic responses to CXCL12 (5-7). The exacerbated CXCR4/CXCL12 signaling notably hampers the trafficking of myeloid cells, results in the retention of hyper mature neutrophils in the bone marrow (i.e. myelokathexis) and affects both innate and adaptive immune responses (8-13). In contrast, the impact of altered CXCR4/CXCL12 axis in NK cells is still poorly defined (14-16). Over the years, WHIM-like disorders showing variations both in genotype and phenotype from the paradigmatic WHIM syndrome have been reported, also including disorders developing in the absence of CXCR4 mutations (13). Here we report B and NK cell anomalies in a female patient with HPV-related disease for whom we have previously proposed a diagnostic hypothesis of WHIM-like syndrome with wild-type CXCR4 (17). The expression of CXCR4 in peripheral lymphocyte subsets and their CXCR4/CXCL12dependent chemotaxis were investigated unveiling a previously unrecognized B lymphocyte defect discrepant with a WHIMrelated response. Together with the identification of anomalies affecting the phenotype and the function of NK cells, our data frame a novel IEI associated with severe HPV infection.

\section{Case Description}

Our patient is a 32-year-old female who was described as a WHIM-like disorder at 26 years of age on the basis of dysplasia of granulocytes, recurrent infections, HPV-associated disease and B-cell lymphopenia (17). As previously reported, no family members showed HPV-susceptibility. However, one brother of four siblings died due to pneumonia at 6 months of age. The patient suffered from recurrent upper respiratory tract infections treated with antibiotic therapy, mostly in the first two decades of life. Later on, HPV-associated disease featured the clinical picture (Figure 1A). Also, early loss of teeth since childhood, periodontal disease and hepatosplenomegaly was present. No autoimmune manifestations were observed. Molecular genetic testing for CXCR4 as well as for GATA2, $N E M O$, and $C D 40 L$, revealed a wild-type status. Moreover, significant data did not emerge from the analysis of a previously described Next Generation Sequencing (NGS) panel that includes well-defined IEI genes $(>300)$ plus many candidate genes associated with critical immune pathways (18), and Whole Exome Sequencing (WES) of the patient and parents (trio). Although in the bone marrow approximately $10 \%$ of neutrophils showed typical multilobed nuclei reminiscent of myelokathexis, the lack of perivascular clusters made us describe it as dysplasia of granulocytes. Moreover, peripheral blood cell counts showed normal values of neutrophils, monocytes, and lymphocytes but high levels of eosinophils. Blood smears revealed hypo-segmented nuclei with long filaments of chromatin connecting nuclear lobes in neutrophils and eosinophils. Repeated immunophenotypic analysis of peripheral blood mononuclear cells (PBMCs), before and after lesion treatment, showed persistent B-cell lymphopenia (3\%), normal distribution of $\mathrm{T}$ - and $\mathrm{B}$-cell subsets except for a gradual increase in $\mathrm{CD} 21^{\text {low }} \mathrm{B}$ lymphocytes (from $13.4 \%$ to $34 \%$ ). Serum immunoglobulin levels, including IgG subclasses and IgE, were within the normal range. Protective anti-pneumococcus IgG levels were detected after polysaccharide vaccine, although they tended to wane over time (17). Also, an adequate humoral and cellular response to COVID-19 vaccine was observed. Over the years, her severe foot and hand cutaneous warts continued to benefit from the treatment attempt with HPV vaccine (three doses and a booster of Gardasil 4 plus three doses of Gardasil 9), although her mucosal lesions persisted (19). Recently, she mostly suffered from severe vulvar and cervical condylomata as well as cervical intraepithelial neoplasia (grade 3), requiring several biopsies and Loop Electrosurgical Excision Procedure, twice. Anal intraepithelial lesions (grade 2) have developed, too. HPV genotyping from cervical biopsies revealed HPV types 6, 18, 51, and 58 .

The cell-surface expression of CXCR4 was comparatively analyzed by flow cytometry on distinct lymphocyte subsets of our patient and an age-matched healthy donor (HD) (for detailed Materials and Methods please see Supplementary Material). The CXCR4 expression level on $\mathrm{CD}^{+}$and $\mathrm{CD}^{+} \mathrm{T}$ lymphocytes was similar in the patient and in HD (Figure 1B). Instead, patient's CXCR4 expression was somewhat reduced on NK cells (30\% lower MFI) but increased on B lymphocytes (47\% higher MFI) as compared with HD cells. We also explored the expression level of CCR7, a chemokine receptor controlling the homing to secondary lymphoid tissues of naïve $\mathrm{T}$ and $\mathrm{B}$ lymphocytes and $\mathrm{CD} 56^{\text {bright }} \mathrm{NK}$ cells, as well as the expression level of CXCR5, controlling homing of B lymphocytes to follicular compartments on secondary lymphoid tissues $(20,21)$. In patient's cells the relative expression level of CCR7 was reduced by 30 to $40 \%$ in $\mathrm{CD}^{+}$ $\mathrm{T}, \mathrm{CD}^{+} \mathrm{T}$, and NK cells as compared with values in HD cells. Finally, relative CXCR5 expression on B lymphocytes was 37\% higher in the patient as compared with HD. 
A

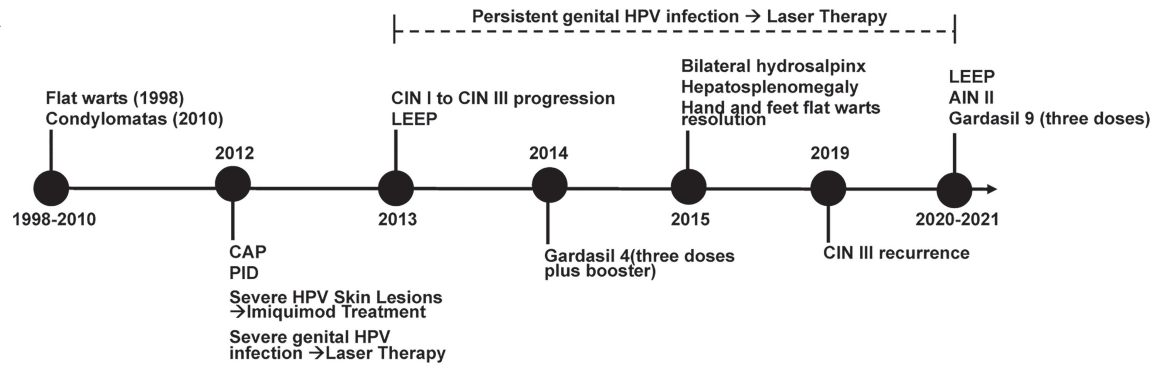

B

$\mathrm{CD}^{+} \mathrm{T}$ cells

$\mathrm{CD}^{+} \mathrm{T}$ cells

NK cells

B cells
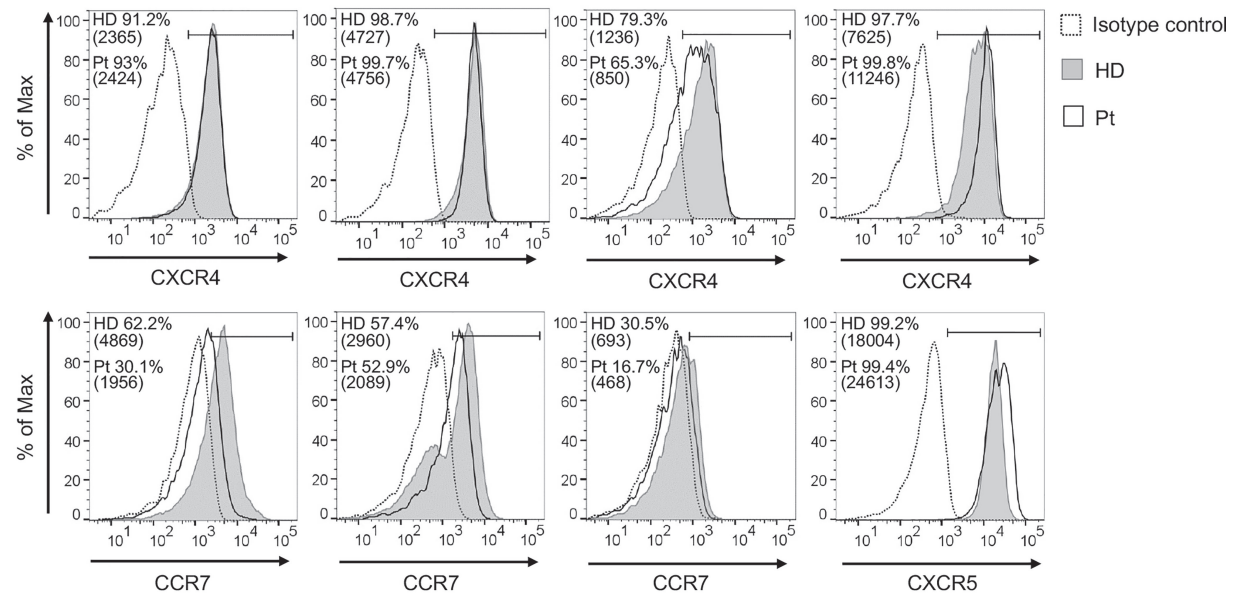

C

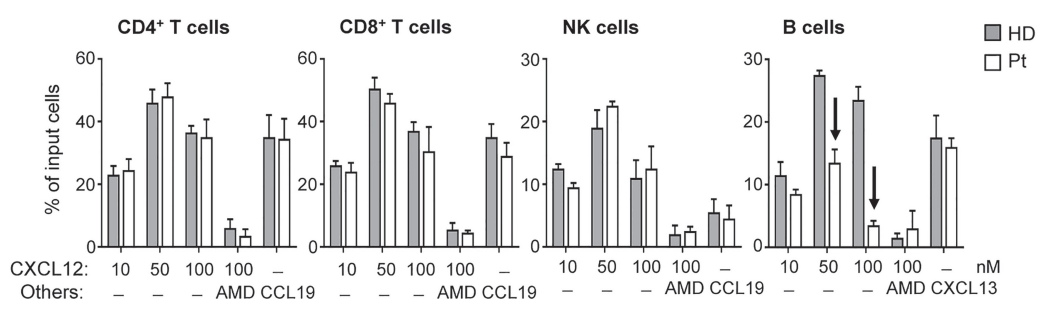

FIGURE 1 | (A) Clinical history of the patient (CAP, community acquired pneumonia; PID, pelvic inflammatory disease; CIN, cervical intraepithelial neoplasia; AIN, anal intraepithelial neoplasia; LEEP, loop electrosurgical excision procedure). Chemokine receptor expression and chemotactic response of blood lymphocyte subsets. (B) Cell surface expression of CXCR4, CCR7 and CXCR5 was analyzed in CD4 ${ }^{+} \mathrm{T}, \mathrm{CD} 8^{+} \mathrm{T}, \mathrm{NK}$, and B cells upon immunolabeling of peripheral blood cells from the patient (Pt; open histograms) and age-matched HD (filled gray histograms). The control lgG signal (dashed lines) is also shown. Values corresponding to percentage of positive cells as well as MFI (in brackets) are reported. (C) The chemotactic response of blood lymphocyte subsets was analyzed using whole blood samples from HD and Pt; results are expressed as percentage of input cells responding to the indicated concentrations of CXCL12, to $100 \mathrm{nM}$ CCL19, or $300 \mathrm{nM}$ CXCL13. AMD: AMD3100. Arrows indicate chemotactic responses notably reduced in Pt as compared with HD.

The transwell migration assay showed that $\mathrm{CD} 4^{+}$and $\mathrm{CD} 8^{+} \mathrm{T}$ lymphocytes as well as NK cells derived from the patient's blood displayed a normal chemotactic response towards CXCL12 (Figure 1C), despite the reduction of CXCR4 expression we observed on patient's NK cells. The observed dose-response effect was CXCL12/CXCR4-mediated as revealed by the inhibition provided by AMD3100, a specific inhibitor of CXCR4. Similarly, the CCR7-dependent chemotactic response to CCL19 of these lymphocyte subsets was equivalent in patient- and HD-derived cells, despite the observed differences in relative CCR7 expression levels. CCR7-dependent chemotactic response of NK cells was modest in conformity with the overall low CCR7 expression level. In contrast, for the patient-derived B lymphocytes, the CXCR4dependent chemotactic response was strongly reduced as compared to HD-derived cells, with a loss of chemotactic efficacy of $51 \pm 7.6 \%$ and $80 \pm 2.8 \%$ in response to $50 \mathrm{nM} \mathrm{CXCL12}$ and $100 \mathrm{nM} \mathrm{CXCL12,}$ respectively (Figure 1C), in spite of increased expression levels of CXCR4 on B lymphocytes. Of note, the response of patient-derived B-lymphocytes to CXCL13, a ligand of CXCR5, was not affected as compared with HD. 
Patient's NK cells had a normal frequency in peripheral blood but their subset distribution was profoundly altered (Table $\mathbf{1}$ and Figure 2A). We observed a striking expansion of CD56 ${ }^{\text {bright }}$ cells (55.6\% vs. median $5.8 \%$ in HDs) at the expense of CD56 ${ }^{\mathrm{dim}}$ cells ( $43.5 \%$ vs. median $87.8 \%$ in HDs). Then, we investigated the phenotype of CD56 $6^{\text {bright }}$ and CD56 ${ }^{\text {dim }}$ subsets in our patient as compared with HDs. Both patient's NK-cell subsets showed increased expression of the CD38 activation marker, albeit CD69 was very low as in HDs' cells (Figure 2B). The vast majority of patient's CD56 ${ }^{\text {bright }}$ cells displayed an immature NKG2 ${ }^{+} \mathrm{KIR}^{-} \mathrm{CD} 57^{-}$phenotype as seen in HD (Figure 2C), with an overall expansion of a CD $56^{\text {bright }}{ }^{2} D 16$

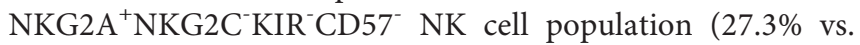
median $2.4 \%$ of HDs) (Table 1). The expression of perforin and of the NKG2D, NKp46, and DNAM-1 activating receptors in patient's CD56 ${ }^{\text {bright }}$ and $\mathrm{CD} 56^{\mathrm{dim}}$ cells was normal, yet the frequency of $\mathrm{NKp} 46^{+} \mathrm{CD} 56^{\text {bright }}$ cells was higher than in $\mathrm{HD}$ (97.6\% vs. 78\%, respectively) (Table 2 ). Moreover, we analyzed the distribution of $\mathrm{CD} 56^{\mathrm{dim}}$ cell maturation subsets which progress from early-differentiated $\left(\mathrm{NKG} 2 \mathrm{~A}^{+} \mathrm{KIR}^{-}\right)$to fully mature (NKG2 $\mathrm{A}^{-} \mathrm{KIR}^{+} \mathrm{CD} 57^{+}$) cells and, eventually, to memory-like (NKG2 ${ }^{-} \mathrm{NKG} 2 \mathrm{C}^{+} \mathrm{KIR}^{+} \mathrm{CD} 57^{+}$) cells, a highly cytotoxic NK cell subset with immune adaptive properties that is expanded in CMV-seropositive individuals (23). Figure 2D shows that our patient had a normal frequency of earlydifferentiated and mature CD56 ${ }^{\text {dim }}$ cells (Table 1), but lacked memory-like CD56 ${ }^{\text {dim }}$ cells despite CMV seropositivity. Next, we analyzed the function of CD56 $6^{\text {bright }}$ and CD $56^{\text {dim }}$ NK cells by measuring their degranulation activity (i.e. CD107a expression) against HLA class I-devoid cell targets (K562 and 721.221 cells) as well as their capacity to produce IFN- $\gamma$ upon stimulation with IL-12, IL-15, and IL-18 cytokines, an NK-cell activity primarily exerted by CD56 ${ }^{\text {bright }}$ cells. As shown in Figures 2E, F, patient's CD56 ${ }^{\text {bright }}$ cells were able to degranulate and accumulate IFN- $\gamma$ in response to cytokines similarly to $\mathrm{HD}$ cells. In contrast, patient's CD56 ${ }^{\text {dim }} \mathrm{NK}$ cells were impaired in their capacity to degranulate against cell targets as compared to HDs.

TABLE 1 | Distribution of NK cells.

\begin{tabular}{|c|c|c|}
\hline & $\begin{array}{c}\text { HDs } \\
25-37 y(n=9)\end{array}$ & $\begin{array}{c}\mathrm{Pt} \\
32 \mathrm{y}\end{array}$ \\
\hline \multicolumn{3}{|l|}{ NK } \\
\hline$\%$ of $\mathrm{PBL}$ & $7.5(6.1-8)$ & 7.7 \\
\hline \multicolumn{3}{|l|}{ NK cell subsets (\%) } \\
\hline CD56 $6^{\text {bright }}$ & 5.8 (3.2-9.3) & 55.6 \\
\hline $\mathrm{CD}^{\mathrm{dim}}$ & $87.8(80.5-88.5)$ & 43.5 \\
\hline CD56 $6^{\text {neg }}$ & $6.5(6.4-8.8)$ & 0.6 \\
\hline $\mathrm{CD}^{\text {bright }}{ }^{\mathrm{C}} 16^{-} \mathrm{NKG} 2 \mathrm{~A}^{+} \mathrm{NKG} 2 \mathrm{C}^{-} \mathrm{CD} 57^{-}$ & $2.4(1.5-3.9)$ & 27.3 \\
\hline \multicolumn{3}{|l|}{ CD56 ${ }^{\text {dim }}$ subsets (\%) } \\
\hline NKG2A ${ }^{+} \mathrm{KIR}^{-}$(early differentiated) & $33.6(12.4-46.2)$ & 23.8 \\
\hline $\mathrm{NKG}^{-} \mathrm{A}^{-} \mathrm{KIR}^{+} \mathrm{CD}^{+} 7^{+}$(mature) & $31.3(13.7-44.4)$ & 30.7 \\
\hline NKG2A-KIR ${ }^{+} \mathrm{CD}^{-} 7^{+} \mathrm{NKG}^{-} \mathrm{C}^{+}$(memory-like) & $2.8(0.5-42.4)^{\star}$ & 0.7 \\
\hline
\end{tabular}

Values are indicated as median (IQR, interquartlile range).

${ }^{*} 1.7(0.1-6)$ and 25(2.5-80) in CMV-seronegative and -seropositive subjects, respectively (22).

$y$, years.

\section{DISCUSSION}

Individuals with IEI may suffer of increased infectious susceptibility either to a specific pathogen or multiple pathogens (24). Here we provide original data on a patient previously proposed as a potential WHIM-like case with disseminated and persistent mucocutaneous HPV infection, recurrent upper respiratory tract infections, B-cell lymphopenia and dysplasia of granulocytes, while in a context of wild-type CXCR4 and normal peripheral neutrophil and monocyte counts $(17,19)$. In line with previous observations made in typical WHIM patients, our patient showed B-cell lymphopenia as prominent immunologic alteration and poor maintenance of memory response to vaccines. In the present study further immunological aspects were investigated in this patient. We found that, as compared with HD, CXCR4 was expressed at normal levels in patient's $\mathrm{CD}^{+}$and $\mathrm{CD}^{+}{ }^{+} \mathrm{T}$ lymphocytes, slightly reduced in NK cells yet it was increased in B lymphocytes. Moreover, we showed that the chemotactic response towards CXCL12 was maintained in patient's T and NK cells but was strongly reduced in B lymphocytes, which is at odds with the typical increased responsiveness of cells derived from WHIM patients (57). Such uncoupling of the expression level of CXCR4 and its chemotactic response has already been described also for $\mathrm{B}$ lymphocytes $(25,26)$. In general, CXCR4 is expressed throughout the whole B lymphocyte ontogeny where it fulfills different functions depending on the developmental stage $(6,27,28)$. Also, mouse models underlined the key role of proper CXCR4 functioning in B-cell lymphopoiesis (29) and in the maintenance of the humoral response (30). We thus hypothesize that patient' $\mathrm{B}$ cell dysfunctions could derive from an altered fine-tuning of the CXCR4/CXCL12 axis responsiveness as a consequence of anomalies in signal transducer(s), which has yet to be identified. Overall, these results reveal additional differences between our patient's clinical and biological manifestations and those of the WHIM syndrome and suggest a novel IEI awaiting for the identification of a genetic defect in the CXCR4 signaling pathway that would account for the cutaneous and mucosal susceptibility to HPV-induced disease.

It is of interest that while our patient had normal frequency of circulating NK cells, an abnormal NK-cell subset distribution with a dramatic expansion of CD56 $6^{\text {bright }}$ cells was observed. Patient's CD56 ${ }^{\text {bright }}$ cells, aside increased CD38 and NKp46 expression that is indicative of an enhanced activation status, presented an immature phenotype and efficient IFN- $\gamma$ producing capability that normally distinguishes this NK-cell subset. In the peripheral blood of healthy subjects, the vast majority of circulating NK cells is CD56 ${ }^{\text {dim }}$, while only a small percentage consists of CD56 ${ }^{\text {bright }}$ cells that mainly reside in secondary lymphoid organs and are considered to be CD56 ${ }^{\mathrm{dim}}$ cell precursors (31). Of note, expansion of the CD56 $6^{\text {bright }}$ subset has been observed in other disease settings including chronic infection and IEI $(32,33)$. As described in IEI cases, our patient showed a high frequency of immature CD16 NKG2A ${ }^{+} \mathrm{NKG} 2 \mathrm{C}^{-} \mathrm{CD}^{-} 7^{-}$cells within the $\mathrm{CD} 56^{\text {bright }}$ subset $(33,34)$. Moreover, $\mathrm{CD} 56^{\text {bright }}$ cell expansion was paralleled by a decrease in both the frequency and the cytotoxic potential of CD56 dim cells. In keeping with more arguments in favor of CD56 ${ }^{\text {bright }}$ cells being the precursors of CD56 $6^{\mathrm{dim}}$ cells (35), it can be postulated the presence in 
A

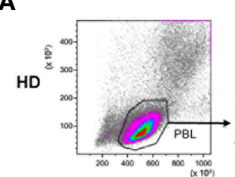

HD
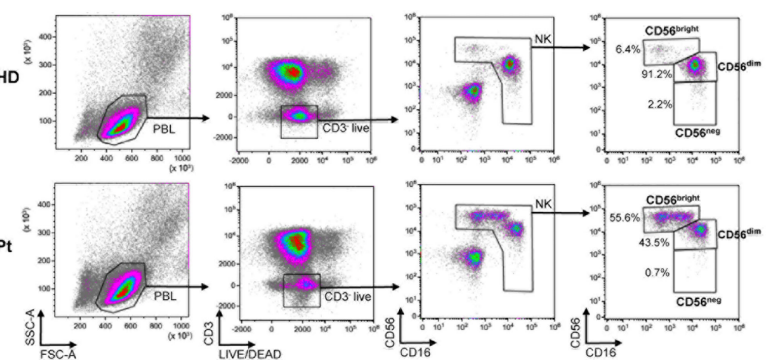

C

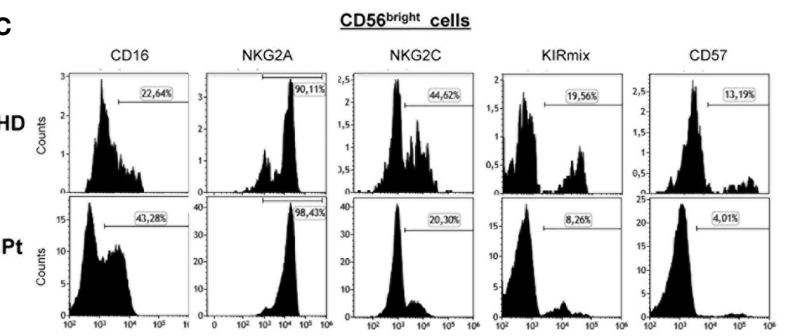

E

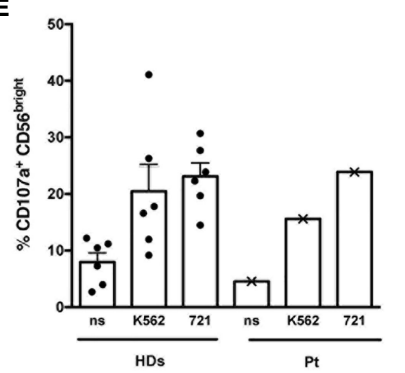

F
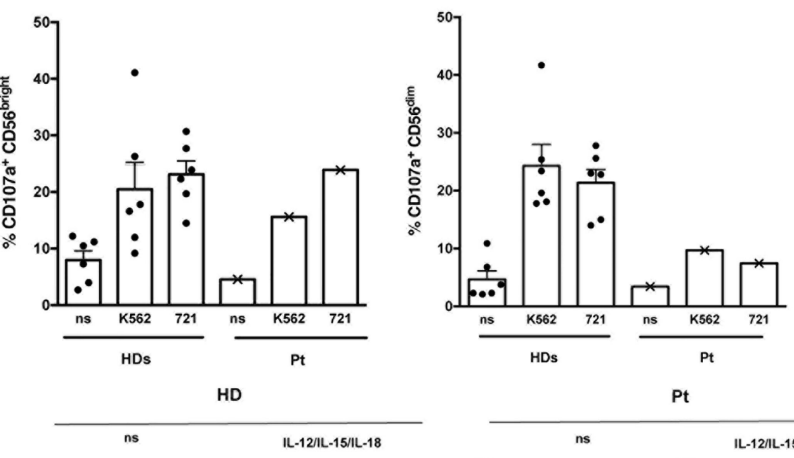

Pt

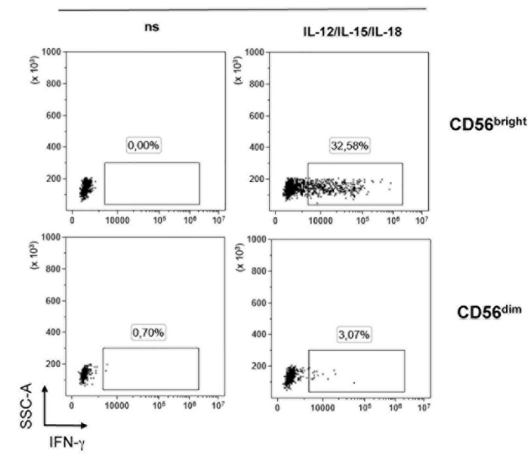

B
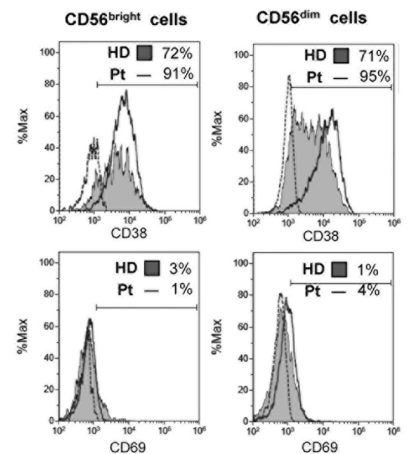

D

HD

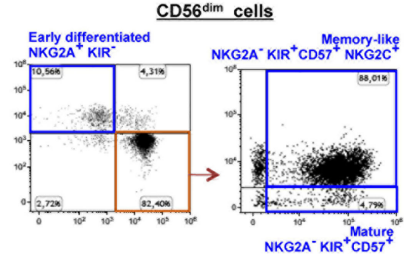

Pt

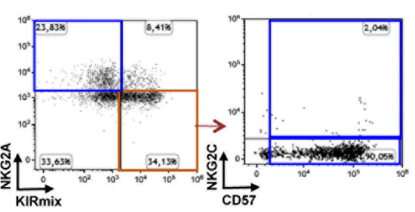

FIGURE 2 | Flow cytometry-based analysis of NK cell subsets. (A) The gating strategy used to identify NK cells among PBMCs and measure the frequencies of $\mathrm{CD}_{6}{ }^{\text {bright }}$, CD56 $^{\text {dim }}$, and CD56 ${ }^{\text {neg }}$ subsets is shown for the patient (Pt) and a representative HD. (B) The frequency of CD38 ${ }^{+}$and CD69 ${ }^{+}$cells in CD56 ${ }^{\text {bright }}$ and CD56 ${ }^{\text {dim }} \mathrm{NK}$ cells from the patient (open histograms) and a representative $\mathrm{HD}$ (filled gray histograms) is shown together with control lgG signal (dashed lines).

(C) Histograms depict expression of CD16, NKG2A, NKG2C, KIR (KIRmix: KIR2DL1/S1/S3/S5 and KIR2DL2/L3/S2), and CD57 on CD56 bright cells gated as shown in panel (A). (D) The gating strategy used to identify different maturation subsets (Early differentiated, Mature, and Memory-like) on the basis of NKG2A, NKG2C, CD57 and KIR expression in CD56 ${ }^{\text {dim }}$ cells gated as described in panel (A) is shown for the Pt and a representative CMV-seropositive HD. (E) Bar plots represent pattern of CD107a expression measured by flow cytometry on gated CD56 ${ }^{\text {bright }}$ (left) and CD56 ${ }^{\text {dim }}$ (right) NK cells of the WHIM-like patient and HDs following 6 hours culture of PBMCs with and without (non stimulated, ns) K562 or 721.221 (721) cell targets. The mean \pm SD of 6 HDs is reported. (F) Dot plots depict intracellular IFN- $\gamma$ expression in gated CD56 ${ }^{\text {bright }}$ and CD56 ${ }^{\text {dim }}$ NK cells following 20 hours culture in the presence or absence (ns) of IL-12, IL-15, and IL-18 of PBMCs derived from a representative $\mathrm{HD}$ and the $\mathrm{WHIM}$-like patient. The percentage of IFN- $\gamma^{+}$cells is reported. 
TABLE 2 | NK-cell activating receptors and perforin profile.

\begin{tabular}{|c|c|c|}
\hline & $\begin{array}{c}\text { HDs } \\
25-37 y(n=9)\end{array}$ & $\begin{array}{c}\mathrm{Pt} \\
32 \mathrm{y}\end{array}$ \\
\hline \multicolumn{3}{|l|}{ CD56 ${ }^{\text {bright }}$} \\
\hline \multicolumn{3}{|l|}{ NKG2D } \\
\hline$\%$ of $N K G 2 D^{+}$ & 73.1 (66.8-79.8) & 49.9 \\
\hline NKG2D MFI & 3626 (1386-5397) & 1381 \\
\hline \multicolumn{3}{|l|}{ NKp46 } \\
\hline$\%$ of $\mathrm{NKp} 46^{+}$ & $78(64.5-87.8)$ & 97.6 \\
\hline NKp46 MFI & 3800 (2785-4434) & 10232 \\
\hline \multicolumn{3}{|l|}{ DNAM-1 } \\
\hline$\%$ of DNAM- $1^{+}$cells & 93.7 (77.4-94.1) & 99.3 \\
\hline DNAM-1 MFI & 14157 (4380-14994) & 7434 \\
\hline \multicolumn{3}{|l|}{ Perforin } \\
\hline$\%$ of Perforin ${ }^{+}$cells & $100(100-100)$ & 99.7 \\
\hline Perforin MFI & $18680(14092-37817)$ & 19054 \\
\hline \multicolumn{3}{|l|}{ CD56 ${ }^{\text {dim }}$} \\
\hline \multicolumn{3}{|l|}{ NKG2D } \\
\hline$\%$ of $N K G 2 D^{+}$ & 62.5 (53.9-79.7) & 66.3 \\
\hline NKG2D MFI & 2358 (1601-4404) & 1277 \\
\hline \multicolumn{3}{|l|}{ NKp46 } \\
\hline$\%$ of $\mathrm{NKp} 46^{+}$ & 83.7 (77.3-88.5) & 88.8 \\
\hline NKp46 MFI & $4100(2960-5441)$ & 5949 \\
\hline \multicolumn{3}{|l|}{ DNAM-1 } \\
\hline$\%$ of DNAM- $1^{+}$cells & 75.4 (71.9-94.5) & 91.8 \\
\hline DNAM-1 MFI & 5629 (5026-7321) & 6159 \\
\hline \multicolumn{3}{|l|}{ Perforin } \\
\hline$\%$ of Perforin ${ }^{+}$cells & $99(97.2-100)$ & 97.6 \\
\hline Perforin MFI & 59279 (31607-100561) & 54597 \\
\hline
\end{tabular}

Values are indicated as median (IQR, interquartlile range).

y, years; NKG2D, Natural Killer Group 2 member D; NKp46, Natural Killer cell p46-related protein; DNAM-1, DNAX Accessory Molecule 1

our patient of a partial maturation block at some step during differentiation from $\mathrm{CD} 56^{\text {bright }}$ to $\mathrm{CD} 56^{\mathrm{dim}}$ cells. Intriguingly, our patient did not present $\mathrm{NKG} 2 \mathrm{C}^{+}$memory-like CD56 ${ }^{\mathrm{dim}} \mathrm{NK}$ cells that are normally expanded in CMV-seropositive individuals as she was $(22,23)$. At present, however, we cannot discern whether our patient has a bona fide NK cell memory defect or belongs to the $4 \%$ of individuals with an NKG2C/NKG2C phenotype where memorylike NK cells should be identified by specific transcriptional reprogramming analysis (36). At any rate, the observed skewing of $\mathrm{CD} 56^{\text {bright }}$ and $\mathrm{CD} 56^{\mathrm{dim}}$ subsets and the impaired cytotoxic potential of CD $56{ }^{\mathrm{dim}} \mathrm{NK}$ cells might have detrimental consequences in the responses towards viral infections as well as tumors.

Studies in vitro and in mouse models have shown that CXCR4/ CXCL12 signaling is important for the development of NK cells, likely instructing NK-cell progenitors towards IL-15 niches formed by mesenchymal stem/progenitor cells (37-39). In particular, CXCR4 desensitization is required for the exit of most immature NK cells from the bone marrow, whereas CXCR4 appears to be dispensable for NK cell trafficking in lymph nodes (14). It is tempting to speculate that a shared molecular mechanism involving an abnormal CXCR4 signaling might have driven the altered differentiation pattern of B and NK cells in our patient, a hypothesis that deserves further investigation. In line with the important role of NK cells in the immune defense against viruses, a clinical hallmark shared by primary NK cell deficiencies is an unusual susceptibility to severe and/or recurrent viral infections, such as herpes virus and HPV infections (40). Therefore, a link may exist between the alteration of the NK-cell compartment and severe and persistent HPV pathogenesis in our patient. Consistent with this hypothesis, it has been reported the case of a woman affected by HPV-associated recalcitrant warts who had a dramatic CD56 $6^{\text {bright }}$ cell expansion associated with low frequency of CD56 ${ }^{\mathrm{dim}}$ cells and impaired NK-cell cytotoxicity. Treatment with IFN- $\alpha$ resulted in warts disappearance and restoration of the NK cell function and subset distribution (41). More recently, it was also reported the case of a man with somatic reversion of an IL2RG germline mutation in T lymphocytes but not in NK cells, presenting recurrent warts and an intranasal HPV-related squamous-cell carcinoma and for whom NK cell included $31 \%$ of CD56 $6^{\text {bright }}$ cells and displayed low cytotoxic function. Allogeneic hematopoietic-cell transplantation allowed normalization of the distribution on NK cell subpopulations and cytotoxic function and also the regression of HPV-related lesions (42). Moreover, killer immunoglobulin-like receptor (KIR) and HLA polymorphisms have been demonstrated to affect the individual susceptibility to various diseases including infections (43). In particular, different studies have shown the association of a specific KIR and/or HLA genotype with either protection against or increased risk for HPV-associated cervical neoplasia $(44,45)$. The occurrence that our patient might present KIR and/or HLA genotype that confers increased resistance of HPV-infected cells to cytotoxic responses needs to be investigated. The key role of CXCR4 in HPV16-induced oncogenesis in an experimental mouse model (46) and in the abnormal NK-cell distribution in a WHIM mouse model (14) support the idea that CXCR4/CXCL12 signaling could play a critical function in the control of HPV infection $(13,46$, 47), with the important assistance of a balanced NK cell distribution and function (40). Turning to a common link governing B and NK cell abnormalities seen in our patient holds promise for the dissection of critical regulators involved in CXCR4/CXCL12 axis.

\section{CONCLUSION AND TRANSPARENCY STATEMENT}

Since the original description of our patient $(17,19)$, extended clinical monitoring as well as immunological and genetic investigations here presented have allowed further understanding of this novel IEI, underscoring the contribution of CXCR4/CXCL12 signaling pathway and of NK cells in host defense against HPV and providing new clues for targeted therapies.

\section{DATA AVAILABILITY STATEMENT}

The raw data supporting the conclusions of this article will be made available by the authors, without undue reservation.

\section{ETHICS STATEMENT}

The studies involving human participants were reviewed and approved by the ethics committee of the Policlinico Tor Vergata, Rome Italy. The patients/participants provided their written informed consent to participate in this study. Written informed 
consent was obtained from the individual(s) for the publication of any potentially identifiable images or data included in this article.

\section{AUTHOR CONTRIBUTIONS}

GMFM and VM conceived the study. GMFM and MS provided clinical samples and patients' clinical data. MD, SC, GDM, and VM-E performed experiments and analyzed the data. MD, GMFM, VM-E, and FB contributed to the study design and data interpretation. MD, GMFM, VM-E, and VM contributed to writing the manuscript. All authors have revised the manuscript and agreed to publish the final version.

\section{FUNDING}

This work was supported by grants of the Association Laurette Fugain to FB and VM-E, and of the Italian Ministry of Health

\section{REFERENCES}

1. Gheit T. Mucosal and Cutaneous Human Papillomavirus Infections and Cancer Biology. Front Oncol (2019) 9:355. doi: 10.3389/fonc.2019.00355

2. de Jong SJ, Créquer A, Matos I, Hum D, Gunasekharan V, Lorenzo L, et al. The Human CIB1-EVER1-EVER2 Complex Governs Keratinocyte-Intrinsic Immunity to $\beta$-Papillomaviruses. J Exp Med (2018) 215:2289-310. doi: 10.1084/jem.20170308

3. Béziat V, Casanova JL, Jouanguy E E. Human Genetic and Immunological Dissection of Papillomavirus-Driven Diseases: New Insights Into Their Pathogenesis. Curr Opin Virol (2021) 51:9-15. doi: 10.1016/j.coviro.2021. 09.002

4. Leiding JW, Holland SM. Warts and All: Human Papillomavirus in Primary Immunodeficiencies. J Allergy Clin Immunol (2012) 130:1030-48. doi: 10.1016/j.jaci.2012.07.049

5. Gulino AV, Moratto D, Sozzani S, Cavadini P, Otero K, Tassone L, et al. Altered Leukocyte Response to CXCL12 in Patients With Warts Hypogammaglobulinemia, Infections, Myelokathexis (WHIM) Syndrome. Blood (2004) 104:444-52. doi: 10.1182/blood-2003-10-3532

6. Balabanian K, Lagane B, Pablos JL, Laurent L, Planchenault T, Verola O, et al. WHIM Syndromes With Different Genetic Anomalies are Accounted for by Impaired CXCR4 Desensitization to CXCL12. Blood (2005) 105:2449-57. doi: 10.1182/blood-2004-06-2289

7. Tassone L, Notarangelo LD, Bonomi V, Savoldi G, Sensi A, Soresina A, et al. Clinical and Genetic Diagnosis of Warts, Hypogammaglobulinemia, Infections, and Myelokathexis Syndrome in 10 Patients. J Allergy Clin Immunol (2009) 123:1170-3, 1173.e1-3. doi: 10.1016/j.jaci.2008.12.1133

8. Kawai T, Malech HL. WHIM Syndrome: Congenital Immune Deficiency Disease. Curr Opin Hematol (2009) 16:20-6. doi: 10.1097/MOH.0b013e32831ac557

9. Rosenzweig SD, Holland SM. Recent Insights Into the Pathobiology of Innate Immune Deficiencies. Curr Allergy Asthma Rep (2011) 11:369-77. doi: 10.1007/s11882-011-0212-9

10. Sokol CL, Luster AD. The Chemokine System in Innate Immunity. Cold Spring Harb Perspect Biol (2015) 7:a016303. doi: 10.1101/cshperspect.a016303

11. Majumdar S, Murphy PM. Adaptive Immunodeficiency in WHIM Syndrome. Int J Mol Sci (2018) 20:3. doi: 10.3390/ijms20010003

12. De Filippo K, Rankin SM. CXCR4, the Master Regulator of Neutrophil Trafficking in Homeostasis and Disease. Eur J Clin Invest (2018) 48 Suppl 2:e12949. doi: 10.1111/eci.12949

13. Heusinkveld LE, Majumdar S, Gao JL, McDermott DH, Murphy PM. WHIM Syndrome: From Pathogenesis Towards Personalized Medicine and Cure. J Clin Immunol (2019) 39:532-56. doi: 10.1007/s10875-019-00665-w
(Ricerca Corrente co-founded by Italian 5 x 1000 from Bambino Gesù Children's Hospital) to MD.

\section{ACKNOWLEDGMENTS}

We acknowledge IPSIT for the support with the facility PLAIMMO (Marie-Laure Aknin) and the Region Ile de France for the financial support of this facility. This work was carried out in the tutorial framework of Master in Advanced Pediatric Allergy and Immunology at University of Rome Tor Vergata.

\section{SUPPLEMENTARY MATERIAL}

The Supplementary Material for this article can be found online at: https://www.frontiersin.org/articles/10.3389/fimmu.2022. 799564/full\#supplementary-material

14. Mayol K, Biajoux V, Marvel J, Balabanian K, Walzer T. Sequential Desensitization of CXCR4 and S1P5 Controls Natural Killer Cell Trafficking. Blood (2011) 118:4863-71. doi: 10.1182/blood-2011-06-362574

15. Bernardini G, Antonangeli F, Bonanni V, Santoni A. Dysregulation of Chemokine/Chemokine Receptor Axes and NK Cell Tissue Localization During Diseases. Front Immunol (2016) 7:402. doi: 10.3389/fimmu. 2016.00402

16. Levy E, Reger R, Segerberg F, Lambert M, Leijonhufvud C, Baumer Y, et al. Enhanced Bone Marrow Homing of Natural Killer Cells Following mRNA Transfection With Gain-Of-Function Variant CXCR4(R334X). Front Immunol (2019) 10:1262. doi: 10.3389/fimmu.2019.01262

17. Moscato GMF, Giacobbi E, Anemona L, Di Cesare S, Di Matteo G, Andreoni M, et al. Dysplasia of Granulocytes in a Patient With HPV Disease, Recurrent Infections, and B Lymphopenia: A Novel Variant of WHIM Syndrome? Front Pediatr (2017) 5:95. doi: 10.3389/fped.2017.00095

18. Cifaldi C, Brigida I, Barzaghi F, Zoccolillo M, Ferradini V, Petricone D, et al. Targeted NGS Platforms for Genetic Screening and Gene Discovery in Primary Immunodeficiencies. Front Immunol (2019) 10:316. doi: 10.3389/ fimmu.2019.00316

19. Moscato GM, Di Matteo G, Ciotti M, Di Bonito P, Andreoni M, Moschese V. Dual Response to Human Papilloma Virus Vaccine in an Immunodeficiency Disorder: Resolution of Plantar Warts and Persistence of Condylomas. J Eur Acad Dermatol Venereol (2016) 30:1212-3. doi: 10.1111/jdv.13133

20. Ebert LM, Schaerli P, Moser B. Chemokine-Mediated Control of T Cell Traffic in Lymphoid and Peripheral Tissues. Mol Immunol (2005) 42:799-809. doi: 10.1016/j.molimm.2004.06.040

21. Pesce S, Moretta L, Moretta A, Marcenaro E. Human NK Cell Subsets Redistribution in Pathological Conditions: A Role for CCR7 Receptor. Front Immunol (2016) 7:414. doi: 10.3389/fimmu.2016.00414

22. Gumá M, Angulo A, Vilches C, Gómez-Lozano N, Malats N, López-Botet M. Imprint of Human Cytomegalovirus Infection on the NK Cell Receptor Repertoire. Blood (2004) 104:3664-71. doi: 10.1182/blood-2004-05-2058

23. Rölle A, Brodin P. Immune Adaptation to Environmental Influence: The Case of NK Cells and HCMV. Trends Immunol (2016) 37:233-43. doi: 10.1016/ j.it.2016.01.005

24. Tangye SG, Al-Herz W, Bousfiha A, Chatila T, Cunningham-Rundles C, Etzioni A, et al. Human Inborn Errors of Immunity: 2019 Update on the Classification From the International Union of Immunological Societies Expert Committee. J Clin Immunol (2020) 40:24-64. doi: 10.1007/s10875019-00737-x

25. Honczarenko M, Douglas RS, Mathias C, Lee B, Ratajczak MZ, Silberstein LE. SDF-1 Responsiveness Does Not Correlate With CXCR4 Expression Levels of 
Developing Human Bone Marrow B Cells. Blood (1999) 94:2990-8. doi: 10.1182/blood.V94.9.2990.421k36_2990_2998

26. Palmesino E, Moepps B, Gierschik P, Thelen M. Differences in CXCR4Mediated Signaling in B Cells. Immunobiology (2006) 211:377-89. doi: 10.1016/j.imbio.2005.12.003

27. Diaz GA. CXCR4 Mutations in WHIM Syndrome: A Misguided Immune System? Immunol Rev (2005) 203:235-43. doi: 10.1111/j.0105-2896.2005.00226.x

28. Bachelerie F. CXCL12/CXCR4-Axis Dysfunctions: Markers of the Rare Immunodeficiency Disorder WHIM Syndrome. Dis Markers (2010) 29:18998. doi: $10.1155 / 2010 / 475104$

29. Nagasawa T, Hirota S, Tachibana K, Takakura N, Nishikawa S, Kitamura Y, et al. Defects of B-Cell Lymphopoiesis and Bone-Marrow Myelopoiesis in Mice Lacking the CXC Chemokine PBSF/SDF-1. Nature (1996) 382:635-8. doi: $10.1038 / 382635 \mathrm{a} 0$

30. Hargreaves DC, Hyman PL, Lu TT, Ngo VN, Bidgol A, Suzuki G, et al. A Coordinated Change in Chemokine Responsiveness Guides Plasma Cell Movements. J Exp Med (2001) 194:45-56. doi: 10.1084/jem.194.1.45

31. Poli $\mathrm{A}$, Michel T, Thérésine $\mathrm{M}$, Andrès $\mathrm{E}$, Hentges $\mathrm{F}$, Zimmer J. CD56bright Natural Killer (NK) Cells: An Important NK Cell Subset. Immunology (2009) 126:458-65. doi: 10.1111/j.1365-2567.2008.03027.x

32. Mace EM, Orange JS. Genetic Causes of Human NK Cell Deficiency and Their Effect on NK Cell Subsets. Front Immunol (2016) 7:545. doi: 10.3389/ fimmu.2016.00545

33. Dobbs K, Tabellini G, Calzoni E, Patrizi O, Martinez P, Giliani SC, et al. Natural Killer Cells From Patients With Recombinase-Activating Gene and NonHomologous End Joining Gene Defects Comprise a Higher Frequency of CD56 (bright) NKG2A(+++) Cells, and Yet Display Increased Degranulation and Higher Perforin Content. Front Immunol (2017) 8:798. doi: 10.3389/fimmu.2017.00798

34. Cifaldi C, Cotugno N, Di Cesare S, Giliani S, Di Matteo G, Amodio D, et al. Partial T Cell Defects and Expanded CD56(bright) NK Cells in an SCID Patient Carrying Hypomorphic Mutation in the IL2RG Gene. J Leukoc Biol (2020) 108:739-48. doi: 10.1002/JLB.5MA0220-239R

35. Domaica CI, Fuertes MB, Uriarte I, Girart MV, Sardañons J, Comas DI, et al. Human Natural Killer Cell Maturation Defect Supports In Vivo CD56(bright) to CD56(dim) Lineage Development. PloS One (2012) 7:e51677. doi: 10.1371/ journal.pone.0051677

36. Lee J, Zhang T, Hwang I, Kim A, Nitschke L, Kim M, et al. Epigenetic Modification and Antibody-Dependent Expansion of Memory-Like NK Cells in Human Cytomegalovirus-Infected Individuals. Immunity (2015) 42:43142. doi: 10.1016/j.immuni.2015.02.013

37. Noda M, Omatsu Y, Sugiyama T, Oishi S, Fujii N, Nagasawa T. CXCL12CXCR4 Chemokine Signaling is Essential for NK-Cell Development in Adult Mice. Blood (2011) 117:451-8. doi: 10.1182/blood-2010-04-277897

38. Bozzano F, Marras F, Ascierto ML, Cantoni C, Cenderello G, Dentone C, et al. 'Emergency Exit' of Bone-Marrow-Resident CD34(+)DNAM-1(Bright) CXCR4(+)-Committed Lymphoid Precursors During Chronic Infection and Inflammation. Nat Commun (2015) 6:8109. doi: 10.1038/ncomms9109
39. Miao R, Lim VY, Kothapalli N, Ma Y, Fossati J, Zehentmeier S, et al. Hematopoietic Stem Cell Niches and Signals Controlling Immune Cell Development and Maintenance of Immunological Memory. Front Immunol (2020) 11:600127. doi: 10.3389/fimmu.2020.600127

40. Mace EM, Orange JS. Emerging Insights Into Human Health and NK Cell Biology From the Study of NK Cell Deficiencies. Immunol Rev (2019) 287:202-25. doi: 10.1111/imr.12725

41. Cac NN, Ballas ZK. Recalcitrant Warts, Associated With Natural Killer Cell Dysfunction, Treated With Systemic IFN-Alpha. J Allergy Clin Immunol (2006) 118:526-8. doi: 10.1016/j.jaci.2006.04.023

42. Lisco A, Hsu AP, Dimitrova D, Proctor DM, Mace EM, Ye P, et al. Treatment of Relapsing HPV Diseases by Restored Function of Natural Killer Cells. N Engl J Med (2021) 385:921-9. doi: 10.1056/NEJMoa2102715

43. Kulkarni S, Martin MP, Carrington M. The Yin and Yang of HLA and KIR in Human Disease. Semin Immunol (2008) 20:343-52. doi: 10.1016/j.smim.2008.06.003

44. Bao X, Hanson AL, Madeleine MM, Wang SS, Schwartz SM, Newell F, et al. HLA and KIR Associations of Cervical Neoplasia. J Infect Dis (2018) 218:2006-15. doi: 10.1093/infdis/jiy483

45. Carrington M, Wang S, Martin MP, Gao X, Schiffman M, Cheng J, et al. Hierarchy of Resistance to Cervical Neoplasia Mediated by Combinations of Killer Immunoglobulin-Like Receptor and Human Leukocyte Antigen Loci. J Exp Med (2005) 201:1069-75. doi: 10.1084/jem.20042158

46. Meuris F, Gaudin F, Aknin ML, Hémon P, Berrebi D, Bachelerie F. Symptomatic Improvement in Human Papillomavirus-Induced Epithelial Neoplasia by Specific Targeting of the CXCR4 Chemokine Receptor. J Invest Dermatol (2016) 136:473-80. doi: 10.1016/j.jid.2015.11.004

47. Maciejewski-Duval A, Meuris F, Bignon A, Aknin ML, Balabanian K, Faivre L, et al. Altered Chemotactic Response to CXCL12 in Patients Carrying GATA2 Mutations. J Leukoc Biol (2016) 99:1065-76. doi: 10.1189/jlb.5MA0815-388R

Conflict of Interest: The authors declare that the research was conducted in the absence of any commercial or financial relationships that could be construed as a potential conflict of interest.

Publisher's Note: All claims expressed in this article are solely those of the authors and do not necessarily represent those of their affiliated organizations, or those of the publisher, the editors and the reviewers. Any product that may be evaluated in this article, or claim that may be made by its manufacturer, is not guaranteed or endorsed by the publisher.

Copyright (c) 2022 Doria, Moscato, Di Cesare, Di Matteo, Sgrulletti, Bachelerie, Marin-Esteban and Moschese. This is an open-access article distributed under the terms of the Creative Commons Attribution License (CC BY). The use, distribution or reproduction in other forums is permitted, provided the original author(s) and the copyright owner(s) are credited and that the original publication in this journal is cited, in accordance with accepted academic practice. No use, distribution or reproduction is permitted which does not comply with these terms. 